\title{
Quem gosta de Opere Mondo? ${ }^{1}$
}

Alfonso Berardinelli

Este livro de Franco Moretti, Opere Mondo, é um livro admirável, importante, mas que entendo só pela metade e do qual no fundo eu não gosto. Vou imitar o estilo de Moretti, que procede a partir de perguntas e respostas, perguntando-me "por quê?" e tentando responder. Mas para evitar o clímax negativo e o final trágico, dando relevo aos aspectos negativos do texto, vou fazer o contrário. Primeiro as coisas negativas e, em seguida, para concluir, as coisas positivas que penso desse livro. Um final de comédia, agradável e leve, me parece, ademais, mais adequado a uma obra disposta a quase tudo para mostrar que a evolução literária, e mesmo a social, caminham em direção ao melhor, e que valia a pena sempre perder algo de essencial para ganhar em desenvolvimento livre. Não sabemos, realmente, se o advento da modernidade foi mais uma festa ou um luto, se o século XX foi uma explosão criativa ou destrutiva. Eu admito que sou sensível ao lado negativo da coisa e que vejo mais o que foi perdido do que os novos ganhos. Moretti, no entanto, sublinha sempre a destruição de vínculos do passado como uma libertação. O seu livro concede pouca margem à incerteza. E eis que posso começar pelo último dos quatro porquês, o pior.

Por que não gosto deste livro? Não gosto porque... tenho sempre a impressão de que Moretti me joga numa armadilha. O livro é de fato uma grande, potente, engenhosa armadilha crítica. Contém as iscas mais atraentes, os maiores autores, os mais discutidos, as obras que não se pode deixar de percorrer: do Fausto até Cem Anos de Solidão, como diz o subtítulo. Mas, em seguida, os dois pontos cruciais são Wagner e Joyce, os artífices das mais sortudas e perfeitas opere mondo, ou seja, O Anel de Nibelungo e Ulysses.

Pode parecer banal, mas, para ser franco, tenho que dizê-lo. Não gosto da idéia de que a opera mondo mais bem realizada deva ser também, segundo Moretti, aquela de maior sorte, e que, portanto, em literatura e em arte o melhor produto é aquele que vence a concorrência do mercado, é aquele mais competitivo. Interessam-me e despertam a minha curiosidade muito mais os casos em que, ao contrário, o que é de melhor qualidade (opere mondo ou não) é negligenciado e recusado, porque isso estimula a crítica e mostra os aspectos não positivos, mas negativos da sociedade burguesa, mercantil, capitalista, moderna e pósmoderna: da sociedade total e de massa. Qualidade e sucesso, no entanto, para Moretti, andam juntos. As opere mondo são as obras que foram impostas como "textos sagrados" da literatura moderna. E, portanto, o melhor da cultura artística se une em um abraço feliz com os estágios culminantes do desenvolvimento social, e vence porque é mais forte.

Tenho que acrescentar, porém, que, além dessa idéia de opera mondo, não gosto nada das opere mondo peculiares às quais Moretti se refere com entusiasmo. Fico entediado com o Fausto e com o Ulysses, detesto sua massacrante preeminência, acho Wagner antipático e não consigo escutá-lo, pela pretensiosa solenidade na qual cada nota se afoga, e, enfim, 
não me parece que Cem Anos de Solidão seja aquela obra-prima que consideram: um livro que após as primeiras cem páginas se torna monótono e previsível, uma orgia açucarada. É verdade, diria Moretti. Mas... segundo ele, é exatamente isso que os torna opere mondo e textos sagrados: justamente o tédio, a necessidade que esses livros impõem, ou seja, de serem estudados mais que lidos, fortes mais que agradáveis, importantes e de massacrante presença no campo cultural, mais que nutritivos, confortáveis, reveladores para o leitor simples ou para uma elite de leitores. A opera mondo não é, como se dizia antes, artisticamente bem acabada. Não é um sucesso artístico, e sim um sucesso sociológico. A sua importância não se explica com a medida da arte em si, mas com a medida da relação entre arte e sociedade. Uma opera mondo é uma obra que cumpre a missão de amarrar milagrosamente (e consegue, por um triz!) aquilo que na esfera cultural e artística e na experiência social custava a encontrar forma. Tento resumir alguns conceitos (e valores) que mantêm de pé o livro de Moretti. A opera mondo, contrariamente àquilo que se poderia acreditar à primeira vista, não é uma obra que cria um mundo à parte, não cria uma outra dimensão em relação àquela do presente social, mas é aquela que resolve, no entanto, conflitos e dificuldades presentes na experiência social, tornando-os aceitáveis. Ela não se opõe ao mundo, não o desmascara, não o julga, tanto menos denuncia seus horrores e os aspectos grotescos e ridículos. Não, a opera mondo torna aceitável o mundo social que, até pouco antes, ou em outras obras menos fortes (e, portanto, menos conscientes), parecia inaceitável.

A opera mondo sabe que o mundo social é dominado pela força e pelo poder e se dirige a ele usando os mesmos meios, poder e força, pelo medium da forma. A opera mondo é a obra que tem a mesma forma assumida vez por outra na sociedade pela força que governa o mundo social.

É disso que eu não gosto na idéia que Moretti tem da literatura maior enquanto opera mondo: não gosto que a literatura, no seu verdadeiro cume, quando vence os seus concorrentes e se torna texto sagrado, não tenha feito outra coisa que se modelar ao poder, na forma do poder social. A opera mondo, pode-se dizer, ergue um altar ao poder, de modo que os leitores também possam adorá-lo, adorá-lo na experiência estética, além de, por força das circunstâncias, na experiência social cotidiana.

Agora é possível de se entender um pouco melhor porque, na minha opinião, de gustibus disputandum. A crítica de Moretti, uma forma de crítica que toma asceticamente a forma do estudo científico, parece não levar em consideração problemas de gosto e de valor, com os relativos julgamentos. Os julgamentos de gosto e de valor são nele implícitos, de forma que a minha descrição do seu livro poderia lhe parecer absurda. Ele de fato acredita que está fazendo ciência. Na minha opinião, no entanto, Moretti constrói um mito e pratica um moralismo. A uma certa altura diz que, obviamente, falando por inciso, ele também tem as suas preferências (prefere Joyce a Proust e, me parece, também a Kafka enquanto eu prefiro Proust e Kafka).

Suas preferências e gostos, no entanto, prefere não expressar da forma mais direta e desarmada: conserva-os e os ultrapassa, tornando-os fortes e objetivos, com um ato de Aufhebung. O estudioso engole o leitor e o faz desaparecer. Do leitor, que está na sua barriga, ele extrai alguns nutrientes, algumas motivações. Mas tem que escondê-lo para torná-lo cientificamente potente, institucionalmente respeitável. É o "modelo historiográfico 
darwiniano", é a teoria "materialista" da literatura que se encarrega de tornar vencedoras as preferências e os gostos, que, por serem pessoais, passíveis de opinião, e, portanto, cientificamente inaceitáveis, "disformes", não devem aparecer.

Voltando ao "não gosto", é que não gosto do caráter de demonstração inderrogável, que, na crítica de Moretti, assumem suas inegáveis, mas por ele negadas e relegadas à sombra, preferências.

Lembro com simpatia um ensaio de Auden a propósito de Ler. Uma das epígrafes é tirada de Paul Valéry, e diz: "só se lê bem apenas aquilo que se lê com um intuito totalmente pessoal. O que pode servir tanto para adquirir algum poder, como para alimentar ódio em relação ao autor". Com "ódio amável” Moretti estuda suas opere mondo para entender "como funcionam", ou seja, como adquiriram seu poder, ainda que sejam e pareçam freqüentemente falimentos parciais, ou obras-primas falidas. Falimentos e obras não acabadas no plano artístico, mas sucessos sociais, formas darwinianamente vencedoras.

A idéia de opere mondo inspira também a idéia que, pelo menos nesse livro, Moretti tem da crítica, ou melhor, dos “estudos literários". A sua forma de crítica é aquela hoje vencedora; o estudo acadêmico, materialista e comparado, teórico e aplicado, deve substituir as formas da crítica anterior, de tipo ensaístico, já sem muito espaço e autoridade, e há tempos em declínio. A sua forma de crítica é aquela que se constituiu a partir do estudo (chamado) científico da literatura: para um público de leitores que não se perguntam e não devem se perguntar se gostam ou não de um determinado livro ou se ele tem maior ou menor valor que um outro. A crítica de Moretti gosta de falar a um público de leitores obrigados, mais que a ler, a estudar livros como textos sagrados.

Essa apoteose da crítica que declina e depois acaba, para daí se tornar estudo acadêmico, teórico e comparado, e dos leitores livres que se tornam leitores obrigados institucionalmente, será também um processo em curso, quase irrefreável. Mas não gosto e não consigo vê-lo com bons olhos. Será realidade, mas espero que não seja toda a realidade, ou seja, o único modo de se relacionar com as obras literárias.

Lembrava-me daquele ensaio de Auden sobre leitura e sobre crítica, porque preferiria que as preferências de um crítico fossem humildemente explicitadas, e, portanto, passíveis de opinião como pessoais e idiossincráticas, em vez de sublimadas e escondidas sob a armadura do estudioso que nos fala apenas de fatos objetivos. Segundo Auden, o crítico deveria, por honestidade, fazer até mesmo a lista detalhada das coisas de que ele gosta (como clima, religião, forma de governo, tipo de arquitetura e de móveis, passa-tempos etc.), de tão importante que é saber quais são os gostos de quem nos está falando com autoridade sobre obras literárias.

Apenas numa ocasião Moretti é mais explícito sobre esse ponto, e é quando nos diz que fazer "história materialista das formas literárias", "entender como funcionam aquelas coisas complicadas que os seres humanos gostam de ler" é uma coisa que lhe dá, "com toda a franqueza", "um prazer irracional". ${ }^{2}$

Essa franqueza rude de Moretti é uma das qualidades mais preciosas da sua escritura crítica: mas é uma pena, para não dizer uma contradição, falar de "prazer irracional", exatamente no momento em que se faz desaparecê-lo dentro "da história materialista das formas literárias". Será tão “irracional” assim esse prazer? Com uma simpática despretensão, 
Moretti acrescenta que não tentará "de forma alguma justificá-lo". Não, justificá-lo não. Mas é estranho que exatamente no momento em que se fala de "como funcionam" as obras literárias, evite-se ver que também o prazer crítico de "quebrá-las em pedaços" (essa expressão um pouco forte é usada na página 70) faça ver como funciona e que é muito pouco irracional.

O prazer do crítico que sufoca o leitor e se sublima em estudioso é o prazer de sentir a literatura como coisa morta, ou como uma máquina sobre a qual se realizam obrigatoriamente dissecações e desmontagens. É o prazer do distanciamento garantido (pelos instrumentos de análise) e autorizado (pela instituição de ensino e pesquisa). (O gênio do conhecimento para Moretti é frio; para mim, é quente).

E aqui volto ao início da minha resposta, ao porquê de eu não gostar, nesse livro, do modo como se entende a crítica e se lê a literatura. Eu falava em sermos atirados por Moretti numa armadilha crítica. Sim, mas por quê? Porque para Moretti as próprias obras literárias são armadilhas perigosas. Não é um caso que o seu mito crítico seja a irreverência agressiva. Deve-se ser mau para poder conhecer, a inteligência é maldade, ou seja, interrupção da simpatia que poderia nos ligar às obras literárias, ou, no máximo, cumplicidade competitiva para a conquista do poder cultural.

É sobre esse terreno que a crítica (o livro de Moretti é, quer ser, uma verdadeira opera mondo crítica) compete hoje com o poder das obras literárias. "A história literária é um campo de batalha"3 e, portanto, a luta deve continuar e ser impiedosa. Seja porque hoje a literatura parece freqüentemente fraca e doente, principalmente na Europa e no Ocidente, e, portanto, é assassinada criticamente. Seja porque as obras literárias são más conosco, enganando-nos. São máquinas para enganar, engenhos formais para produzir ilusões e conciliação. Mas a crítica não cai nessas armadilhas: desmonta-as, vê como funcionam e as imita, reproduzindo o engenho num outro plano.

Moretti desmonta a armadilha literária e constrói uma armadilha crítica. Teoriza as opere mondo como formas darwinianamente vencedoras, para aprender a construir a forma, darwinianamente vencedora, da crítica teórico-comparatista, inspiradas por teóricos da forma e por teóricos da sociedade moderna, e na qual se trata dos livros mais academicamente ineludíveis dos últimos dois séculos. Assim, por aqui nós teremos que passar. Ele tem que ler o Fausto e o Ulysses. Nós temos que ler Moretti. O qual encontrou o modo de tornar argumentativamente obrigatórios os seus gostos, escondendo-os, colocando-os como um anão deformado dentro do poderoso robô da teoria formalista e materialista da evolução dos gêneros. E enfim os seus gostos e as suas argumentações irão abraçar a realidade atual em geral, e não somente a realidade pessoal do Moretti professor de literaturas comparadas em Nova Iorque. Vendo o modo no qual as opere mondo são descritas, do Fausto ao Ulysses, pilastras literárias dos últimos dois séculos, é difícil não fazer vir à mente que Moretti está mesmo fazendo apologia de três coisas: da cidade de Nova Iorque (cume de época), da Universidade (meta final e destino inexorável da literatura que se tornou estudo da literatura) e, enfim, do Pós-Moderno (no qual finalmente as angústias européias da modernidade conflitual se resolvem na pacífica, libertária e polifônica convivência de tudo com tudo).

Estamos próximos de Umberto Eco. A opere mondo de Moretti é uma dilatação potencializada da obra aberta de Eco. Uma obra sem centro antropomórfico: fim do 
personagem, fim da narração romanesca, superação do ensaísmo e de toda inteligência crítica, interessada ainda em compreender e não só "capturar estímulos". O humano-terreno "sai de cena"4 - diz Moretti com satisfação. Restam os objetos, e uma pluralidade de linguagens sem sujeito, objetivadas; uma grande complicação ou complexidade (termo sobre o qual Moretti insiste com crescente satisfação) "sem estro" cultura sem sabedoria, provavelmente demente ou burra. Mas isso quer dizer serem adequados à realidade assim como ela se tornou. A cultura objetiva do capitalismo vence a Bildung subjetiva, e o indivíduo desaparece, com as absurdas pretensões de ter uma consciência própria e uma vida própria. A opera mondo triunfa assim nos esplendores sinistros, mas grandiosos, de uma conciliação final entre arte e sociedade: "A libertação da polifonia" (procedimento cardinal da opera mondo) é, sim, - escreve Moretti - o desenvolvimento da técnica literária, mas um desenvolvimento que recalca em âmbito formal "uma tendência geral do capitalismo moderno" ". A grandeza heróica da opera mondo, que para Moretti é o melhor da literatura moderna, consiste na euforia com que organiza a destruição da própria distância crítica e utópica do mundo, fazendo, ao contrário, da literatura uma apologia da estrutura social.

Uso de propósito essa bem conhecida fórmula adorniana. Eliminar da idéia de literatura moderna a idéia de uma crítica social e culturalé de fato um ponto de honra do livro. Flutua-se com a ajuda do stream joyciano, num grande rio de mercadorias, não alienantes, mas confortantes, carregadas de promessas indefinidas. O fluxo de consciência do Ulysses é, na opinião de Moretti, o procedimento literário vencedor do século XX, porque treina a aceitar o mar de mercadorias, e a mergulhar sem reservas no seu fluxo. É o êxito final dessa história das relações entre obras mundiais e capitalismo e a economia-mondo adocicada pela publicidade. No plano mais estreitamente cultural, o excesso de complexidade se simplifica com o fim dos meios racionais entre uma noção e outra, e com o fim do romance, que é a representação dos nexos entre um antes e um depois, entre um tempo e um espaço, entre um pensamento e um comportamento.

O mundo profetizado pelas opere mondo é, no entanto, um mundo social espacializado, unicompreensivo, sem destino, livre de vínculos, que não teme mais nenhum tribunal moral, político, histórico, religioso. As suspeitas angustiantes e os pesadelos de Kafka, representante máximo (com Proust e Musil) da literatura como parábola e como sabedoria (talvez inapreensível ou não passível de atuação), Moretti considera superados. Esquecendo um pouco, parece-me que o século XX não foi apenas o século das metrópoles e das cosmópoles na qual todos são mais livres, do desenvolvimento dos mercados, das maravilhas da ciência e da tecnologia; foi o século dos totalitarismos, das falsas liberdades, da tecnologia mais destrutiva. Falar ainda, como faz Moretti, da ruptura dos vínculos e dos limites como de um caminho triunfal para a libertação ilimitada (de um sujeito humano, aliás, que se libertou de si mesmo) parece-me uma utopia fulgurante do marxismo do século XIX. Talvez há algum tempo, em vários campos, é, no entanto, exatamente o sentido do limite a coisa de que se sente mais falta. Sob os despojos da teoria literária, esse livro de Moretti soa freqüentemente como um tratado de moral, que quer nos dizer qual é verdadeiramente a realidade, como é feita, e como temos que funcionar para reconhecê-la e ir ao encontro dela. 
Eu desconfio mais dos moralismos implícitos, que falam em nome da dura realidade, do que dos mais inofensivos moralismos explícitos, que encontram a coragem de falar em nome de uma coisa tão frágil e passível de opinião como a moral. Moretti fala com freqüência em nome da realidade, e pensa que a melhor literatura seja aquela das obras que se expandem sobre a realidade, conquistando-a à força. Conquistam-na espelhando-a e obedecendo-a. Essa idéia de literatura, na qual os clássicos canonizados na escola se fundem com os best sellers da Trivialliteratur, agrada a quem adora a realidade entendida como força e a literatura como coisa grande e poderosa: como uma central elétrica, uma rede ferroviária, um aeroporto, uma instituição pública. Mas há também uma literatura que joga sobre um outro plano: na definição do que é a realidade, em ocupar-se do pouco visível, do que é negligenciado e aparentemente secundário, em dirigir-se a leitores individuais, mais que, como as opere mondo, a uma "sociedade inteira" ". Prefiro uma literatura que leve em conta a minúscula liberdade do leitor mais que a força obrigatória das grandes instituições.

Por que entendo só pela metade? Não acredito que a paixão de Moretti por aquilo que é grande, maior, grandioso, por aquilo que arrebata, vence e abraça tudo, seja apenas megalomania. Impossível entender o que ocorre em dois séculos de literatura se se olha riachos e pântanos ignorando rios e lagos. O que eu entendo, no entanto, só pela metade, é por que as opere mondo seriam aquelas e não outras. Segundo a idéia de Moretti, a opera mondo espacializa a pluralidade temporal em pluralidade de lugares compresentes. Ela fratura o tempo e o curso da história. Eis porque o romance permanece excluído do esquema. Assim Balzac, Dickens, Dostoiévski, Tolstói, Zola (que, para não falar de outros, realizaram a épica da realidade quantitativamente mais ampla) não são levados em consideração por estarem muito ligados aos limites de um só espaço nacional. Mas se trata, parece-me, de uma distinção sutil, talvez pretextual. Não consigo considerar o mundo de Baudelaire mais restrito e unívoco do que o mundo de Whitman, nem Guerra e Paz menos polifônico que Moby Dick. Penso (não sei se é uma suspeita) que a exaltação que Moretti faz da pluralidade e da polifonia seja paradoxalmente um pouco unificante demais e unidirecional. Ela privilegia as obras que, por si mesmas, ou pelo modo como são interpretadas por ele, prenunciam o pós-moderno. Nessa categoria de pós-moderno Moretti não se detém muito. Mas acredito que esteja muito sugestionado por ela, e que esteja, em parte, em dívida com Jameson, em parte polemizando com ele. O pós-moderno, quero dizer, entendido como uma estrutura em que muitas coisas, provenientes dos mais diversos espaços e lugares, convivem sem exclusão recíproca e sem conflito: é essa a fisionomia característica das opere mondo. Além da sua semelhança final (ou coincidência no que diz respeito a Ulysses) com a "obra aberta" de Umberto Eco, a teorização de Moretti é levada a gravitar toda sobre o pós-moderno. A opera mondo hegemônica e central do século XX, o Ulysses, é exaltada, porque é capaz de zerar as hierarquias entre objetos e linguagens, reconsagrando esteticamente os lugares comuns e a bêtise social que obcecavam Flaubert.

A épica moderna é "a épica da socialização"8 e o êxito dessa épica quer que o herói desapareça no fluxo das percepções pré-conscientes que instauram como um absoluto o domínio do social, "fora dele" e "dentro dele". A épica moderna abraça, como já dissemos, o mar das mercadorias mentalizadas, culturalizadas pela publicidade. Trata-se, na opinião de Moretti, 
de aceitar inteligentemente a estupidez que a cidade-mundo exige para que se possa sobreviver a ela. Trata-se também, no entanto, de ver que gênero de inteligência é aquela que impõe a aceitação (com feliz distração e sem resistência e julgamento, sem seleção e sem ordem sintática) da estupidez da Cosmópolis das Mercadorias. É preciso, segundo Moretti, conservar-se naquele nível no qual se calam finalmente tanto as mensagens do inconsciente quanto as pretensões da consciência.

O inconsciente de fato arrisca impor ao sujeito inexoráveis exigências interiores e algumas necessidades de natureza (o determinismo psíquico de Freud). E a consciência arrisca interferir de maneira incômoda criando obstáculos ou atritos ao grande imperativo de sintonizar-se felizmente, plasticamente, com o absoluto social (uma sociedade se torna uma perfeita "segunda natureza").

Joyce realiza (aqui está, parece-me, o cume estético-moralista do livro) o procedimento mágico que liberta do julgamento racional e cultural da consciência e liberta daquela incógnita cheia de leis misteriosas que é o inconsciente. Essa é a mensagem pedagógica da opera mondo Ulysses, épica que, segundo Moretti, diz o "sim" definitivo do sujeito ao mundo moderno. (Mas eu duvido que seja exatamente esse, ou acima de tudo esse, o significado do monólogo de Molly). Aqui, ao que me parece, esse mundo moderno assume a forma do pós-moderno americano. E aqui Moretti cita a conhecida frase de um personagem de Wenders: "Os americanos colonizaram o nosso inconsciente". Frase que eu também considero fundamental, talvez num sentido menos positivo que Moretti. (Seria necessário precisar de que América se trata: a América como épica da produção e do mercado, ou a América como épica da liberdade e da democracia? As duas coisas estão sim juntas, mas não coincidem).

Entendo e compartilho de muitos problemas que Moretti coloca em seu livro: o interesse pela história dos gêneros literários, a relação entre arte e sociedade, as vicissitudes da socialização dos indivíduos e o que a propósito nos dizem os personagens da literatura moderna, o conflito e a oscilação de estímulos literários, em direção à vanguarda e o modernismo centrífugo, e em direção à volta do clássico. O que entendo pouco é por que Moretti sentiu necessidade de mobilizar e desacomodar tanta grande literatura para sustentar uma moral da fábula que consiste na apologia da sociedade atual dominada pelo capitalismo americano, sociedade que, aliás, ao que me parece, ele idealiza, e muito. De resto, diz no último capítulo, falando de Garcia Márquez, que se a periferia pobre do mundo adora como uma divindade a tecnologia ocidental, por que obstinar-se a criticá-la? Pode ser verdade que hoje "a absolvição venha da vítima" e que Nova Iorque parece para muitos o ponto final da evolução humana, mas isso não torna de forma alguma supérfluo o potencial crítico expresso pela literatura (o que, aliás, a cultura americana continua a saber muito bem).

A coisa curiosa, que entendo só pela metade, é que o próprio Moretti que louva a conciliação entre literatura e sociedade, entre indivíduo e instituições públicas, entre interioridade e publicidade, até o desaparecimento da literatura, do indivíduo e da interioridade; que esse mesmo Moretti seja tão pouco conciliador e polifônico quando se ocupa de literatura. É quase como se só na literatura o perturbasse a liberdade de uso descompromissada ou idiossincrática, a compresença dos usos e dos modelos. Moretti exalta a pluralidade, as possibilidades infinitas de significado, o abrir-se aos mais diversos 
estímulos, de forma a mantê-los "todos presentes, em primeiro plano, sem perder nenhum"10. E, no entanto, ele pratica uma crítica-estudo que apaga a crítica-leitura. Faz do discurso crítico uma estrutura argumentativa que gostaria muito de parecer uma demonstração sem escapatórias: por isso, verdadeiro ou falso, aut aut, essa obra significa isso e não aquilo, tertium non datur.

Lanço uma hipótese. Talvez Moretti atribua à literatura um poder de controle e coesão social, uma força ideológica que me parece ter se perdido há algum tempo. Não, isso ele sabe, e às vezes diz: a literatura escorregou para a periferia do sistema cultural. Mas e daí? É isto: não é a literatura que é engajada ideologicamente, mas o estudo científicoacadêmico da literatura, o seu uso institucional. O livro de Moretti quer ser uma opera mondo no campo e na linguagem da crítica, quer manter unidos passado, presente e futuro, mas principalmente dominar e manter juntas as várias instâncias culturais que, na prática do estudo literário, podem se resolver no presente. $\mathrm{O}$ autor quer manter juntas as obras imprescindíveis, as diferentes literaturas, o problema forma-sociedade, a teoria dos gêneros, o estilo de cientista, as imagens fortes que fazem sentir toda questão como decisiva, e enfim, uma retórica martelante da crítica como ciência, com o ritmo da argumentação cuidadosamente dividido (as páginas de Moretti fervilham de interrogações e respostas, um mar de problemas, mesmo onde não eram vistos, e um mar de soluções que não se acreditava que fossem necessárias; os parágrafos com freqüência se sucedem como coblas capfinidas: o início do seguinte repete uma palavra, um conceito, uma frase com a qual terminava o anterior).

Quero dizer que Moretti é um ensaísta muito hábil e consciente, um construtor de mitos. Um reitor, às vezes. Excessivamente protagonista, como intérprete de grandes obras. Consegue quase colocá-las à sua sombra, graças à sua agudeza e ao seu vigor problemático. Quebra as obras, agita-as e as espreme para fazer sair o suco que lhe serve para alimentar o enredo apaixonante do discurso crítico. Não, não é um desconstrucionista (não gosta de Derrida, e concordamos nisso). Mas às vezes me pareceu sentir nesse livro uma certa sanha interpretativa: quase como se o discurso crítico, para se estruturar energicamente e se manter firmemente de pé, tivesse que não intensificar o nosso contato com as obras, mas desmontar e usar seus pedaços para a vantagem do discurso crítico. Enfim, parece que Moretti de fato esteja propondo uma ensaística de estudo, gestual e teatralizada, como herdeira da literatura.

Que outro texto pode hoje desfrutar as vantagens da autoridade institucional como um rico e engenhoso livro de crítica acadêmica? É proposta a opera mondo crítica enquanto obra obrigatória, obra que se deve ler. E de fato nós estamos aqui discutindo-a, ainda que nunca possamos chegar a discutir realmente tudo aquilo que o livro de Moretti contém. Trata-se de um livro inesgotável, que nos toca e nos arrebata, e que se torna obrigatório. Mas, por outro lado, nunca poderemos discuti-lo senão escrevendo em resposta um livro do mesmo empenho e das mesmas proporções. Atrapalhamo-nos com as nossas objeções parciais e genéricas. O livro de Moretti está aí, vencedor. E nós somos derrotados, ainda que não gostemos dele e o entendamos apenas pela metade.

Pergunto-me a essa altura por que um livro que torna a ensaística e a interpretação crítica tão protagonistas não tenha levado em consideração a tradição ensaística moderna e as muitas opere mondo que produziu: Voltaire, Tocqueville, Ruskin, De Sanctis, Marx, épica 
das idéias e das formas sociais. Por que perseguir o herói que não age, quando a verdadeira grande Bíblia e Ilíada do mundo moderno é uma obra de ensaística: a Encyclopédie de Diderot e d'Alembert? Se o verdadeiro herói do Ulysses e do Fausto não é um personagem mas um procedimento formal (alegoria, polifonia, stream of consciousness), então o campo de pesquisa deveria talvez pelo menos em parte ser mudado de lugar em favor da ensaística onde, como se sabe, se pode também ser narração, mas os personagens são mais escassos e prevalecem as idéias. Como ensaísta escritor de mitos, Moretti é herdeiro de uma tradição que ignora, ou da qual não fala.

Por que este é um livro importante? A essa pergunta já respondi em parte ou já comecei a responder. Moretti elaborou uma idéia de forma literária, a opera mondo, que ele mesmo aplicou no campo da crítica. A elaboração teórica e histórica da idéia de opera mondo literária toma corpo por sua vez como opera mondo crítica.

Poderia um livro como esse não ser importante? Muitas das incertezas, das fraquezas atuais da crítica (entre desconstrucionismo desenfreado, exibicionismo, e volta à probidade filológica) são aqui encaradas e, de forma especial, resolvidas. O livro tem um equilíbrio instável, mantendo juntas à força coisas demais, e fingindo resolver problemas que permanecem em aberto. Mas é exatamente por isso que nos captura. É um grande cruzamento de lugares comuns da crítica e da teoria literária. Assemelha-se, na verdade, a uma metrópole, a uma central elétrica, a rede ferroviária, a um aeroporto internacional. Podemos não gostar dele, mas ignorá-lo pode ser custoso, colocar em dificuldade, obrigar a procurar alternativas ainda mais trabalhosas e cansativas para ele. E depois, ele fala de teoria literária falando de evolução do capitalismo moderno, detém-se discutindo problemas de ideologia e de técnica literária fazendo-nos entrar de novo no tecido de uma dezena de obras-primas. Opere Mondo alarga os horizontes do discurso crítico até o limite extremo. E faz respirar a nossa cultura, ainda que, em seguida, queira nos pegar pelo pescoço, com um aperto, um pouco prepotente, para nos obrigar a dizer sim. É esse um livro-Harpia, que quer agarrar com garras firmes a nossa Alma. Que nos quer dar o conforto da conciliação com uma gravata, mas que obriga a fazê-lo com as garras de um princípio de realidade demonstrado verdadeiro e poderoso dentro da lógica. Podemos não aceitar nem os escopos de Moretti nem o seu modo de proceder, mas são questões não fúteis, encaradas com uma energia intelectual rara, até desmedida.

Por que é admirável? É evidente, portanto, que se trata de um livro admirável. Dizia, tentando escapar da armadilha moralista que o livro incorpora, que o estudioso Moretti, armado pelos seus instrumentos críticos, engula e esconda o Moretti leitor, com seus gostos de que não compartilho. Agora acrescento alguma coisa que corrige o que foi dito. Acho admiráveis os livros de Moretti, antes de mais nada, porque estão carregados de autobiografia, de maneira alguma exibida, aliás bem escondida. Atrás de cada problema literário que Moretti encara há sempre um problema moral e autobiográfico.

Por exemplo: como crescer, como sair da juventude sem traí-la e encarando o fim das ilusões, como tornar produtivo o desencanto através de um duro trabalho e uma corajosa assunção de responsabilidades. Um problema pessoal se tornava no romance de formação ${ }^{11}$, estudo de um ramo especial do gênero romance (talvez o seu ramo principal). Esse é um livro excelente e poderia dizer, magnificamente inspirado. De 1985 até hoje me parece que 
para Moretti tenha se iniciado uma outra vicissitude pessoal e uma outra busca: o distanciamento da Itália, a elaboração lenta das suas leituras e das suas preferências, a recusa cada vez mais nítida do narcisismo de massa, a busca de nexos entre a sua paixão por certos aspectos da cultura alemã (atrás de Goethe se vê e se vislumbra Mann, Lukács, Adorno, o amado Weber, Freud e, enfim, o marxismo crítico racionalista, aristotélico, antihumanista e anti-utopista, e enfim neoliberal) e os seus estudos de cultura inglesa (atrás de Joyce se vê ou se vislumbra Umberto Eco, estudioso e propagandista do Ulysses na Itália, os formalistas, as vanguardas, a centralidade e a obrigatoriedade acadêmica dos discursos intermináveis sobre o stream of consciousness).

No seu percurso, Moretti não esquece, não perde e não desperdiça nada sem ter antes refletido longamente. A sua crítica, a sua construção de compromisso entre exaltação da polifonia ilimitada e demonstrações críticas muito contingentes, poderá também soar estranha para mim. Mas é algo admirável, e há nela muito o que aprender.

Despedida. Este é, portanto, um livro para quem quer aprender nos lugares em que se deve aprender, onde entre um leitor e um livro há sempre um professor, um cientista, portanto, um guardião autorizado da interpretação, talvez atlético, em mangas de camisa, um eterno rapaz eternamente genial que escreve na lousa a equação da relação entre literatura e sociedade moderna, e que rabisca no chão os nossos hábitos de leitores. Essa atmosfera de escola, esse espírito esportivo trazido no conhecimento e na leitura das obras literárias, infelizmente, tenho que dizer, hoje me dá um pouco de náusea. Penso em Stendhal, quando escreve: "Caro amigo, muitas vezes parte dos homens despreza a graça. É próprio dos ânimos vulgares apreciar só aquilo do que se tem um pouco de temor. Daí a universal consideração apreciada, em sociedade, da glória militar, e, no teatro, do gênero trágico". Daí, eu acrescentaria, o respeito que hoje incutem a teoria, a ciência literária, a terminologia problemática, a retórica da análise. Uma crítica que não incute temor já não interessa.

\section{Notas}

1 Reproduzimos a nota que antecedeu a publicação do texto na revista Paragone:

As páginas que se seguem foram lidas por Alfonso Berardinelli no dia 20 de dezembro de 1994 na Faculdade de Letras da Universidade de Veneza. A redação de Paragone ficou por muito tempo na dúvida entre inseri-las no Giornale ou publicá-las com os ensaios. Trata-se de uma comunicação nascida e concebida como apresentação do livro de Franco Moretti, Opere Mondo [Saggio sulla forma epica dal Faust a Cent'Anni di Solitudine, Torino, Einaudi, 1994.] . A ocasião que a determinou, o acento e o vigor polêmico, o tom aceso e "oral" nos levam a publicá-la na seção normalmente destinada aos assuntos de atualidade, uma vez que a força e a amplitude das idéias, que vão muito além dos limites da cerimônia que as gerou, tornam-nas um verdadeiro ensaio, que mereceria encontrar lugar, com todo o seu fogo, na seção reservada aos textos de maior reflexão. [N. do E.]

2 F. MORETTTI, Opere Mondo. Saggio sulla forma epica dal Faust a Cent'Anni di Solitudine, Torino, Einaudi, 1994, p.7.

3 Ibid. p.140.

4 Ibid. p.196.

5 Ibid. p.197.

6 Ibid. p.184.

7 Ibid. p.209. 
Remate de Males - 25(1) - jan./jun. 2005

8 Ibid. p.153.

9 Ibid. p.235.

10 Ibid. p. 152.

11 F. MORETTI, Il Romanzo di Formazione, Milano, Garzanti, 1985. [N.do E.] 